\title{
Race, Substance Abuse, and Mental Health Disorders as Predictors of Juvenile Court Outcomes: Do They Vary By Gender?
}

Chiquitia Welch-Brewer

Cleveland State University

Patricia A. Stoddard Dare

Cleveland State University, p.stoddarddare@csuohio.edu

Christopher A. Mallett

Cleveland State University, c.a.mallett@csuohio.edu

Follow this and additional works at: https://engagedscholarship.csuohio.edu/clsowo_facpub

Part of the Social Control, Law, Crime, and Deviance Commons, and the Social Work Commons How does access to this work benefit you? Let us know!

Publisher's Statement

(c) 2011 Springer Science and Business Media.

\section{Recommended Citation}

Welch-Brewer, Chiquitia; Stoddard Dare, Patricia A.; and Mallett, Christopher A., "Race, Substance Abuse, and Mental Health Disorders as Predictors of Juvenile Court Outcomes: Do They Vary By Gender?" (2011). Social Work Faculty Publications. 3.

https://engagedscholarship.csuohio.edu/clsowo_facpub/3

This Article is brought to you for free and open access by the School of Social Work at EngagedScholarship@CSU. It has been accepted for inclusion in Social Work Faculty Publications by an authorized administrator of EngagedScholarship@CSU. For more information, please contact library.es@csuohio.edu. 


\title{
Race, Substance Abuse, and Mental Health Disorders as Predictors of Juvenile Court Outcomes: Do They Vary By Gender?
}

\author{
Chiquitia L. Welch-Brewer • Patricia Stoddard-Dare • \\ Christopher A. Mallett
}

\begin{abstract}
Predicting juvenile court outcomes based on youthful offenders' delinquency risk factors is important for the adolescent social work field as well as the juvenile justice system. Using a random sample of 341 delinquent youth from one Midwestern urban county, this study extends previous research by examining if race, substance abuse, and mental health disorders influence important delinquency outcomes (number of court offenses, felony conviction(s), probation supervision length, detention length, and number of probation services) differently for male and female juvenile offenders. Multivariate analysis findings revealed that race was significant only for males, and having a substance use disorder was a stronger predictor of delinquency outcomes for males; whereas, having a mental health disorder was a stronger predictor of delinquency outcomes for females. Implications for this research include the importance of early disorder identification and subsequent availability of gender-focused treatment.
\end{abstract}

Keywords Race $\cdot$ Gender $\cdot$ Juvenile court $\cdot$ Mental health $\cdot$ Substance abuse . Intervention

\section{Introduction}

Substance use and mental health disorders are widespread among youth involved in the juvenile justice system, affecting between 40 and $70 \%$ of this population (Shufelt and Cocozza 2006; Teplin et al. 2006; Timmons-Mitchell et al. 1997; Wasserman et al. 2004). Prevalence estimates suggest that one of out every five youth involved in the juvenile justice system has serious mental health problems

C. L. Welch-Brewer · P. Stoddard-Dare · C. A. Mallett $(\bowtie)$

School of Social Work, Cleveland State University, 2121 Euclid Avenue, \#CB324, Cleveland, OH 44115-2214, USA

e-mail: c.a.mallett@csuohio.edu 
(Cocozza and Skowyra 2000). Most juvenile offenders meet criteria for at least one mental health disorder. The range of mental health disorders and difficulties includes depression, attention and hyperactivity, behavioral control, anxiety, substance abuse, bipolar, and trauma. Disruptive disorders (including conduct, attention-deficit hyperactivity and oppositional defiant) and substance use disorders are the most commonly diagnosed disorders among males and females in the juvenile justice system (Shufelt and Cocozza 2006; Teplin et al. 2006; TimmonsMitchell et al. 1997; Wasserman et al. 2004).

Prevalence and patterns of mental health and substance disorders appear to differ by gender in juvenile justice populations. Findings of research studies have consistently shown that females in the juvenile justice system have higher rates of mental health problems or disorders than do their male counterparts (Abrantes et al. 2005; Cauffman 2004; Kataoka et al. 2001; McCabe et al. 2002; Timmons-Mitchell et al. 1997). In the oft-cited study conducted with a sample of 1,829 detained youth, Teplin et al. (2002) found that $60 \%$ of males compared to $70 \%$ of females met criteria for one psychiatric disorder. And in a more recent multi-state prevalence study conducted by Shufelt and Cocozza (2006), 80\% of females, compared to 67\% of males, met criteria for at least one disorder. Similarly, systematic reviews show that females involved in the juvenile justice system have higher rates of mental health disorders than males. For example, in their systematic review of 25 studies, involving 16,750 youth in detention and juvenile correctional facilities, Fazel et al. (2008) found that $11 \%$ of boys compared to $29 \%$ of girls were diagnosed with major depression; $12 \%$ of boys compared to $19 \%$ of girls were diagnosed with ADHD; and boys and girls had similar rates of diagnosis for a conduct disorder (53\%).

Comparative studies on prevalence estimates of substance use disorders/ problems by gender have been less conclusive. For example, Teplin et al. (2002) found no significant differences in the proportion of males (51\%) compared to females (47\%) in meeting criteria for a substance use disorder. Similarly, Wasserman et al. (2004) found no significant differences between males (26\%) and females $(22 \%)$ in their sample of probation-involved youth. Conversely, Timmons-Mitchell et al. (1997) found that a higher proportion of males (88\%) had a substance use disorder than did females (56\%) in their sample of incarcerated youth. Kim and Fendrich (2002) found that females in their sample were more likely than their male counterparts to endorse indicators of severe or chronic drug use, but males were more likely to engage in frequent drug use than females.

Prevalence and patterns of mental health and substance disorders appear to differ across race in populations of juvenile justice involved youth as well. Teplin et al. (2002), who stratified their sample of 1,829 detained youth by race and gender, found that $82 \%$ of Caucasian males compared to $65 \%$ of African-American males and $70 \%$ of Hispanic males met criteria for a mental health disorder. For females, $86 \%$ of Caucasian females compared to $71 \%$ of African-American females and $76 \%$ of Hispanic females met criteria for a mental health disorder (including a substance use disorder). Similar patterns were found across gender (by race) for substance use disorders. For males, significantly more Caucasian males met criteria for a substance use disorder than did non-Caucasian males. Similarly, for females, more Caucasian females met criteria for a substance use disorder than did non-Caucasian females. 
Correspondingly, Cauffman (2004) found that in her sample of 18,607 detained youth, Caucasian youth reported more mental health problems, as measured by the Massachusetts Youth Screening Instrument (MAYSI), than did Hispanic and African-American youth. Cauffman conducted separate analyses by race and gender, finding that Caucasian males and Caucasian females reported more mental health problems than did their non-Caucasian male and non-Caucasian female counterparts. Overall, findings revealed that African-American youth, irrespective of gender, were least likely to report mental health problems. In a study conducted with a state-based sample of incarcerated youth, Vaughn et al. (2008) found that Caucasian youth had a higher prevalence of meeting criteria for a mental health diagnosis, a higher level of psychiatric symptoms, and a higher prevalence of substance use and substance-related problems than did African-American youth.

Despite variations in patterns and prevalence estimates across gender and race, it is well established that mental health and substance use disorders are common in populations of juvenile justice-involved youth, and are key correlates of delinquent behavior (Hawkins et al. 1998) and recidivism (Grisso 2008). Little is known, however, if the function of race, and substance use and mental health disorders on select juvenile court outcomes vary by gender. Drawing on gender-responsive perspectives, this study seeks to examine which variables (race, substance abuse, and mental health) are related to particular court outcomes for males and females. Having this understanding allows social workers and other stakeholders to design effective targeted prevention and intervention strategies.

Gender-responsive perspectives start from the position that the experiences, needs, and strengths of males and females should be considered in the design and development of gender-responsive interventions because females and males respond differently to interventions (Bloom et al. 2002; Covington and Bloom 2006). Gender responsive perspectives are based on the premise that similar risk factors appear to promote delinquency among male and female youth, but the level and rate of exposure and sensitivity to certain risk factors may differ across gender (Zahn 2007). From a gender-responsive perspective, it is important to understand factors that are common, distinct, and sensitive to both genders. In light of this view, analyses should include independent variables common and distinct to male and female delinquency, and incorporate dependent variables that capture differences in juvenile court outcomes across gender (Johansson and Kempf-Leonard 2009). In addition, the current study draws on the intersectional perspective, specifically the constructs of race and gender. The intersectional perspectives focus on the multiple identities of race, gender, and class. This perspective suggests that "not all girls' experiences within the juvenile justice system are the same; their experiences vary by race and gender...not all African Americans' experiences in the system are the same, but they vary by gender, class and sexuality" (Leiber 2009, p. 335).

In the current study, de-identified data (covering a three-year period) from existing juvenile court records of one large, urban Midwest county juvenile court were used to examine the differential influence of race, substance use, and other mental health disorders on several juvenile court outcomes in males and females. Specifically, the following research question was asked: Do race, substance abuse, and mental health disorders influence number of court offenses, felony 
conviction(s), probation supervision length, detention length, and number of probation services differently for male and female juvenile offenders?

\section{Method}

Sample and Procedures

The sampling frame for this study was one large, urban Midwest county juvenile court population. Compared to other counties in the state, the county selected for the current study has the largest number of juvenile offenders. Three years of data were included in the sampling frame (2006-2008). The annual county juvenile court population averaged 2,300 youth; therefore, the sampling frame totalled 6,900 probation cases.

An apriori analysis was conducted to calculate an appropriate sample size for the current study. It was determined that a sample size of 360 would provide a $5 \%$ margin of error and $95 \%$ confidence interval, assuming a population proportion of $50 \%$. Cases were selected randomly using an electronic number table. The initial sample consisted of 342 unduplicated cases from the county's juvenile court's 2006-2008 population (2006, $N=100 ; 2007, N=137 ; 2008, N=105)$. One case was eliminated as an outlier; therefore, the final sample comprised 341 youth (253 males and 88 females). Of the 253 males comprising the sample, $72 \%$ were AfricanAmerican; of the 88 females, 69\% were African-American. The mean age of the males in the sample was $15.5(\mathrm{SD}=1.7)$ and the mean age of females in the sample was $15.3(\mathrm{SD}=1.4)$.

\section{Data Collection}

Data were collected from administrative case records associated with each youth in the study sample. Specifically, the county juvenile court provided files, which contained juvenile court histories, probation supervision case files, and mental health assessments, for youth selected for the sample. Data from the case records were coded and entered into a statistical software package. Each case entered was evaluated for proper coding and correct data entry. Inter-coder reliability was high (.96).

\section{Measures}

For the purpose of the current study, separate analyses were conducted for males and females. Thus, the variable of gender was neither an independent nor control variable. A total of three independent variables and five dependent variables were measured. Independent variables included race, substance abuse, and mental health disorders.

All independent variables were measured dichotomously. Race was coded 0 for non-African-American and 1 for African-Americans. Approximately 4\% (14) of the sample was Asian or Hispanic, these youth were coded as non-African-American 
along with Caucasian youth. Substance abuse was coded 0 for no substance use disorder (lifetime abuse or dependence) and 1 for a substance use disorder (lifetime abuse or dependence); mental health was coded 0 for no DSM-IV diagnosed mental health disorder (excluding substance use disorder) and 1 for a diagnosis of a DSMIV mental health disorder (excluding substance use disorders). Substance abuse and mental health assessments, which were conducted by licensed providers, using the DSM-IV were derived from case records. The reliability and validity of the DSM IV is well established (American Psychiatric Association 2000).

Continuous dependent variables included number of court offenses, probation length, days in detention, and probation services. For all measured court outcomes, each youth's entire juvenile court history (i.e. multiple offenses over time) was counted. Number of court offenses was a tally of the number of offenses for which the youth was adjudicated delinquent. Probation length was the number of months the youth was under supervision. Days in detention were the number of days the youth was held in the detention center. For the variables probation length and days in detention, multiple offenses were combined and the total number of months each youth was under probation supervision and the total number of days each youth was detained in the detention center were tallied. Probation services were the number of probation services offered to the youth while under court supervision. One dichotomous dependent variable was measured-history of a felony conviction. Felony conviction was coded as 0 (for no current or previous conviction) and 1 for yes (current or previous conviction). Official court records undergo much scrutiny and are presumed to be valid and reliable as much as the court can confirm reported and public information. Intercoder reliability of the information from the court records was high (.96).

\section{Data Analysis}

Univariate analyses were conducted to assure an adequate number of subjects for each variable. Variables were selected based on theory (Bloom et al. 2002; Covington and Bloom 2006; Zahn 2007) and previously identified empirical relevance (Holman and Ziedenberg 2006; Mallett 2009). To examine the influence of race, mental health disorders, and substance use disorders on select court outcomes of juvenile offenders for males and females, a series of multiple regression equations and logistic regression models were computed. The equations were computed separately for males and females. This permitted an examination of how the predictor variables (race, substance abuse, and mental health disorders) differentially impacted court outcomes by gender.

\section{Findings}

Prevalence of Substance Use and Mental Health Disorders: Gender Differences and Similarities

The findings revealed that among the males, $26 \%$ met criteria for a substance use disorder and 55\% met criteria for a mental health disorder. Among the females, $26 \%$ 
Table 1 Type of mental health disorder by gender

\begin{tabular}{lrrrrr}
\hline Mental health disorder & \multicolumn{2}{l}{ Males $(N=253)$} & & \multicolumn{2}{c}{ Females $(N=88)$} \\
\cline { 2 - 3 } \cline { 5 - 6 } & $N$ & & & $N$ \\
\hline ADHD & 56 & 22 & 24 & 27 \\
Adjustment & 6 & 2 & 3 & 3 \\
Anxiety & 6 & 2 & 3 & 3 \\
Bipolar & 7 & 3 & 14 & 16 \\
Conduct disorder & 28 & 11 & 11 & 24 \\
Depression/dysthymia & 23 & 9 & 21 & 14 \\
Oppositional defiant disorder & 12 & 5 & 12 & 2 \\
PTSD & 7 & 3 & 2 & 24 \\
\hline
\end{tabular}

met criteria for a substance use disorder, and $74 \%$ met criteria for a mental health disorder. It is important to note that some individuals were diagnosed with more than one mental health disorder. As indicated in Table 1, ADHD was the most common mental health disorder for both males and females, followed by depression in females and conduct disorder in males. Because evidence indicates that depression and ADHD are linked to delinquency (Hawkins et al. 1998; Loeber and Keenan 1994; Office of Juvenile Justice and Delinquency Prevention 2010; Takeda 2000) it is not surprising that these disorders are prevalent among females in our sample. There appeared to be similar patterns across gender in the proportion of males and females with adjustment disorder (2\% compared to $3 \%$ ), anxiety (2\% compared to $3 \%$ ), and post-traumatic stress disorder (3\% compared to $2 \%$ ). Dissimilarities in the proportion of males and females with select disorders emerged as well. A higher proportion of females, compared to males, met criteria for bipolar disorder (16\% compared to $3 \%)$ and oppositional defiant disorder (14\% compared to $5 \%$ ).

Prevalence of Substance Use and Mental Health Disorders: Racial Differences and Similarities

Among African-American males, 43 (24\%) met criteria for a substance use disorder and $89(49 \%)$ met criteria for a mental health disorder. Among African-American females, $12(20 \%)$ met criteria for a substance use disorder and 44 (72\%) met criteria for a mental health disorder. Among non-African-American males, 22 (31\%) met criteria for a substance use disorder and $45(64 \%)$ met criteria for a mental health disorder. Among non-African-American females, 11 (41\%) met criteria for a substance use disorder and 21 (78\%) met criteria for a mental health disorder.

As indicated in Table 2, ADHD was the most common mental health disorder for both African- American and non-African-American males followed by conduct disorder and depression/dysthymia. For African-American females, the most common disorders were depression/dysthymia followed by ADHD, and 
Table 2 Type of mental health disorder by gender $\times$ race

\begin{tabular}{|c|c|c|c|c|c|c|c|c|}
\hline \multirow[t]{3}{*}{ Mental health disorder } & \multicolumn{4}{|c|}{ Males $(N=253)$} & \multicolumn{4}{|c|}{ Females $(N=88)$} \\
\hline & \multicolumn{2}{|c|}{$\begin{array}{l}\text { Non-African } \\
\text { American } \\
(N=70)\end{array}$} & \multicolumn{2}{|c|}{$\begin{array}{l}\text { African- } \\
\text { American } \\
(N=183)\end{array}$} & \multicolumn{2}{|c|}{$\begin{array}{l}\text { Non-African } \\
\text { American } \\
(N=27)\end{array}$} & \multicolumn{2}{|c|}{$\begin{array}{l}\text { African } \\
\text { American } \\
(N=61)\end{array}$} \\
\hline & $N$ & $\%$ yes & $N$ & $\%$ yes & $N$ & $\%$ yes & $N$ & $\%$ yes \\
\hline ADHD & 17 & 24 & 39 & 21 & 11 & 40 & 13 & 21 \\
\hline Adjustment & 1 & 1 & 5 & 3 & 0 & 0 & 3 & 5 \\
\hline Anxiety & 1 & 1 & 5 & 3 & 0 & 0 & 3 & 5 \\
\hline Bipolar & 0 & 0 & 7 & 4 & 10 & 37 & 4 & 7 \\
\hline Conduct disorder & 7 & 10 & 21 & 11 & 7 & 26 & 4 & 7 \\
\hline Depression/dysthymia & 7 & 10 & 16 & 9 & 3 & 11 & 18 & 30 \\
\hline Oppositional & 5 & 7 & 7 & 4 & 6 & 22 & 6 & 10 \\
\hline PTSD & 3 & 4 & 4 & 2 & 1 & 4 & 1 & 2 \\
\hline
\end{tabular}

oppositional defiant. For Caucasian females, the most common disorders were ADHD, followed by bipolar, conduct disorder, and oppositional defiant.

\section{Race and Juvenile Court Outcomes}

The results of the findings are illustrated in Tables 3 and 4 . Findings indicate that race was a significant predictor of months on probation $(p=.02)$ and number of probation services for males $(p=.01)$ but not for females. All males had an average of 12.6 months on probation ( $\mathrm{SD}=8.8$ ), and an average of 1.9 probation services $(\mathrm{SD}=1.4)$. However, after controlling for other variables, African-American males received 18 more months on probation, and .5 more probation services compared to non-African-American males. For females and males, race was not a significant predictor of number of court offenses, number of days in detention, or felony conviction.

Substance Abuse and Juvenile Court Outcomes

Findings revealed that having a substance use disorder was a significant predictor of number of probation services for males $(p=.00)$ and females $(p=.00)$. All males averaged nearly two probation services (mean $=1.9, \mathrm{SD}=1.4$ ); whereas, females averaged 2.6 probation services $(\mathrm{SD}=2.1$ ). Males with a substance use disorder received nearly one additional probation service, while females with a substance use disorder received an additional 2.4 probation services. Having a substance use disorder was also a significant predictor of number of court offenses for males $(p=.00)$, but not for females. Males with a substance use disorder had 1.8 more court offenses than males without a substance use disorder. For females and males, having a substance use disorder was not a significant predictor of number of months on probation, days in detention, or felony conviction. 


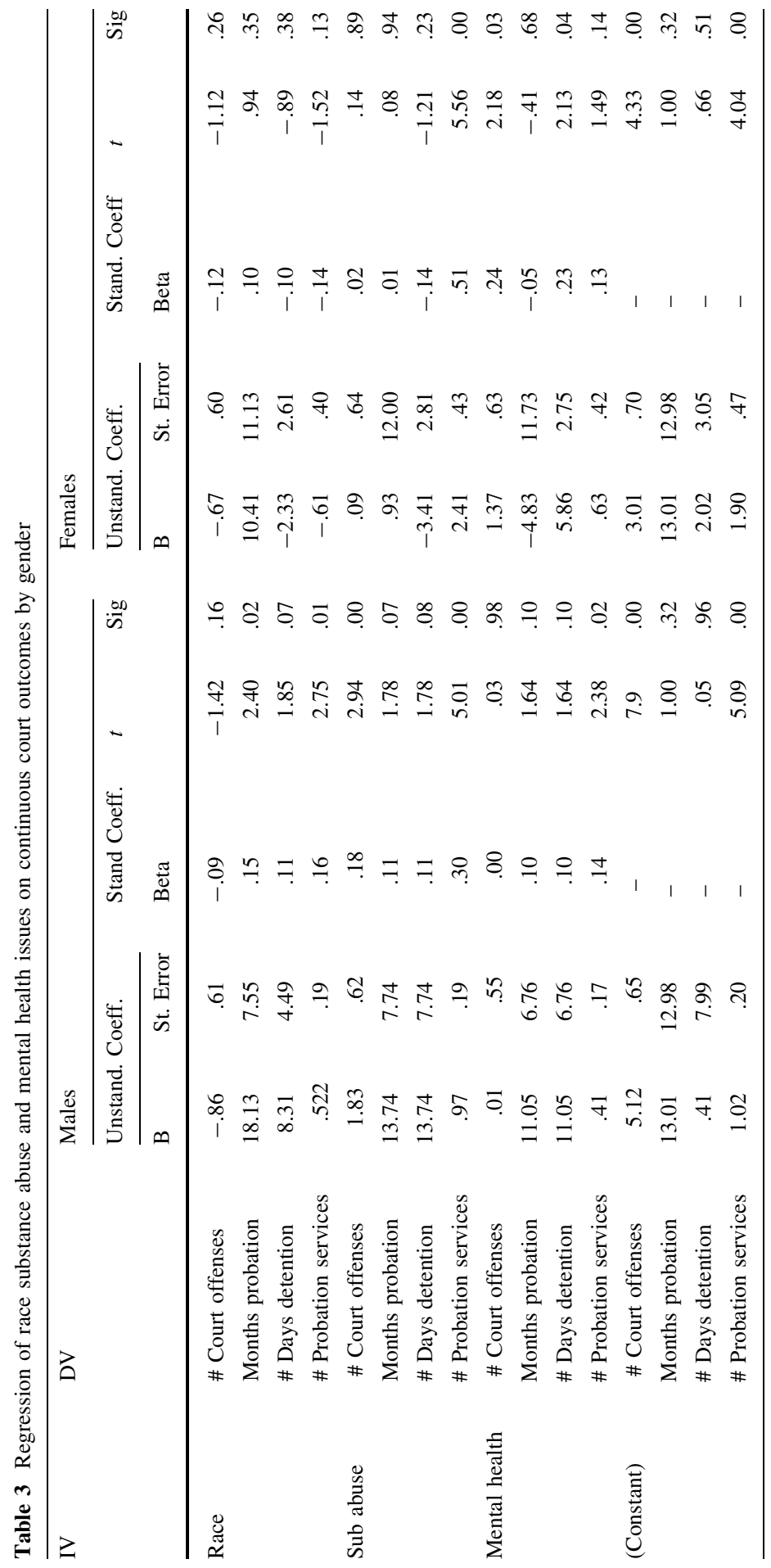


Table 4 logistic regression of race substance abuse and mental health issues on dichotomous felony conviction by gender

\begin{tabular}{|c|c|c|c|c|c|c|c|c|c|c|c|c|}
\hline \multirow[t]{2}{*}{ IV } & \multicolumn{6}{|l|}{ Males } & \multicolumn{6}{|c|}{ Females } \\
\hline & B & SE & Wald & $\mathrm{df}$ & Sig & $\operatorname{Exp}(B)$ & B & SE & Wald & $\mathrm{df}$ & Sig. & Exp (B) \\
\hline Race & .11 & .30 & .13 & 1 & .72 & 1.12 & .30 & .50 & .35 & 1 & .55 & 1.34 \\
\hline Substance abuse & .25 & .32 & .60 & 1 & .44 & 1.28 & .19 & .53 & .13 & 1 & .72 & 1.21 \\
\hline Mental health & -.04 & .28 & .02 & 1 & .89 & .96 & -.12 & .51 & .06 & 1 & .81 & .89 \\
\hline Constant & .66 & .32 & 4.27 & 1 & .04 & 1.94 & -.68 & .58 & 1.38 & 1 & .24 & .51 \\
\hline
\end{tabular}

\section{Mental Health and Juvenile Court Outcomes}

Findings revealed that having a mental health disorder was a significant predictor of number of probation services for males $(p=.02)$ but not for females $(p=.14)$. Males with a mental health disorder averaged .4 more probation services than the average $1.9(\mathrm{SD}=1.4)$ services for males without mental health problems. Additionally, having a mental health disorder was a significant predictor of the number of court offenses $(p=.03)$ and the number of days in detention $(p=.04)$ for females, but not for males (number of court offenses $p=.98$; days in detention $p=.10)$. For females, the average number of court offenses was $5(\mathrm{SD}=4.4)$, and the average time in detention was 17 days $(\mathrm{SD}=44.6)$. However, having a mental health disorder increased the number of court offenses by 1.4, and increased the days in detention by 5.9 more days. For females and males, having a substance use disorder was not a significant predictor of number of months on probation or felony conviction.

\section{Discussion and Implication for Practice}

In the current study, we sought to examine patterns of similarities and dissimilarities across gender on the function of race, substance abuse, and mental health disorders on select juvenile justice court outcomes. Because it was important to contextualize the influence of race, and substance use and mental health disorders on juvenile justice outcomes, we first estimated the prevalence and types of substance use and mental health disorders by gender, then by race, and finally by gender and race. Not surprisingly, our findings revealed that a greater proportion of females than males met criteria for a mental health disorder. For example, $55 \%$ of males and $74 \%$ of females in the sample met criteria for a mental health disorder. These findings closely parallel the prevalence estimates found by Teplin et al. (2002) in a sample of detained youths. Among the males and females in our sample, 26\% met criteria for a substance use disorder. This was substantially lower than the prevalence estimates found in other studies conducted with samples of juvenile-justice-involved youth (Teplin et al. 2002; Timmons-Mitchell et al. 1997). This may be a reflection of different measures used by researchers to examine prevalence estimates in samples of juvenile-justice-involved youth (Timmons-Mitchell et al. 2006). Furthermore, 
similar to the findings of Teplin et al. (2006), our findings revealed that a lower proportion of African-American females met criteria for a substance use disorder and a mental health disorder than non-African-American females. Similarly, a lower proportion of African-American males met criteria for a mental health disorder than non-African-American males. Conversely, unlike the findings of Teplin and colleagues, our findings revealed that a higher proportion of African-American males met criteria for a substance use disorder than non-African-American males.

Our main objective was to examine the influence of race, substance abuse, and mental health disorders on select juvenile justice court outcomes to determine if the findings varied by gender. Overall, our findings revealed dissimilar patterns across gender on select juvenile outcomes, with a few notable exceptions. Race, as a function of juvenile justice outcomes, was a factor only among males; however, it was predictive of substantially longer probation supervision length (18 additional months). In terms of substance abuse and mental health, our findings revealed that having a substance use disorder was the strongest predictor of juvenile justice outcomes for males, whereas, having a mental health disorder was the strongest predictor of juvenile justice outcomes for females. Specifically, for males, having a substance use disorder was a significant predictor of number of court offenses and number of probation services. It should be noted that for both males and females having a substance use disorder was a significant predictor of number of probation services. This pattern of similarity across gender could be attributed to the juvenile court's Drug Court initiative for non-violent youth with a substance use disorder, which is part of a series of county initiatives to reduce overcrowding and to limit admission to the detention center to the most serious youthful offenders. Specifically, for females, having a mental health disorder was a significant predictor of number of court offenses and time in detention. In light of these findings and previous research indicating that substance use problems, mental health problems, and secure detention are linked directly to serious, violent, and chronic offending among females and males (Johansson and Kempf-Leonard 2009), early screening of youth involved in the juvenile justice system for the presence of a substance use and/or mental health disorder is necessary.

Overall, our findings suggest that for females, compared to males, delinquency and mental health are strongly related. Cauffman (2004) noted, "delinquent behavior may select mentally disturbed youth more strongly among girls than among boys" (p. 437). Further research on the relationship between mental health and delinquency among females is needed (Office of Juvenile Justice and Delinquency Prevention 2010). It is important to note that although it appears that a substance use disorder may be a better indicator of delinquency for males than for females and that a mental health disorder may be a better indicator of delinquency for females than for males in our sample, substance use and mental health needs were evident across gender. Differences in substance use and mental health needs and types of mental health needs across race were observed as well. These findings may hold implications for the types of services and interventions that are provided to male and female youth and youth of different racial/ethnic background involved in the juvenile justice system. 


\section{Limitations}

This study has several limitations. First, this analysis utilized existing case files. Although data were evaluated for proper coding and entry, the extent to which there were errors in the original data files is unknown. Second, the sampling frame only represents juvenile court involved youth in one Midwestern county, and although random sampling procedures were used to select cases, our findings have limited generalizability. Third, causal inferences could not be drawn because of the crosssectional design of the study. Another limitation is the possibility that some youth had undiagnosed substance abuse or mental health issues which could compromise the findings. A final limitation is that our study did not measure family or peer risk factors or gender-sensitive factors that have been found to predict youth's delinquent behaviors, indicating a potential for omitted variables bias. Despite these limitations, our findings provide guidance for future research.

\section{Directions for Future Research}

Understanding which variables are related to particular court outcomes for males and females allows stakeholders to design effective targeted prevention and intervention strategies. Given this, there is a need for additional research that examines the extralegal variables of race and gender coupled with factors that have been found to predict children's delinquent behaviors such as substance use and mental health disorders as well as peer and family risk factors. We concur with Schwalbe et al. (2009) that in order to understand fully the demographic variable effects of race, gender, and other factors such as substance use and mental health disorders on juvenile justice court outcomes, "longitudinal studies that follow youths across multiple decision points are required" (p. 38).

Because our findings revealed that males with a substance use disorder and females with a mental health disorder had more offenses that were adjudicated delinquent (which may be a proxy measure of recidivism) than their counterparts without a substance use or mental health disorder, there is a need for further research to determine whether justice-involved youth with a substance use disorder and with a mental health disorder are more likely to reoffend than other types of justice involved youth (Fazel et al. 2008). In particular, there is a need for future studies to examine and identify which types of substance use and mental health disorders are associated with reoffending and to determine if patterns of differences and similarities are observed across gender and race/ethnicity.

In summary, gender-focused treatment for both males and females is necessary. It is important for gender focused-treatment to address similarities and differences between juvenile court involved males and females, as well as address similarities and differences across racial and ethnic groups within each respective gender. Addressing these factors may enhance the treatment outcomes of juvenile justice system involved youth. 


\section{References}

Abrantes, A., Hoffman, N., \& Anton, R. (2005). Prevalence of co-occurring disorders among juveniles committed to detention centers. International Journal of Offender Therapy and Comparative Criminology, 49, 179-193.

American Psychiatric Association. (2000). Diagnostic and statistical manual of mental disorders (4th ed., text revision). Washington, DC: American Psychiatric Association.

Bloom, B., Owen, B., Deschenes, E., \& Rosenbaum, J. (2002). Improving juvenile justice for females: A statewide assessment in California. Crime and Delinquency, 48(4), 526-552.

Cauffman, E. (2004). A statewide assessment of mental health symptoms among juvenile offenders in detention. Journal of the American Academy of Child and Adolescent Psychiatry, 43, 430-439.

Cocozza, J., \& Skowyra, K. (2000). Youth with mental health disorders: Issues and emerging responses. Office of Juvenile Justice and Delinquency Prevention Journal, 7(1), 3-13.

Covington, S. S., \& Bloom, B. (2006). Gender-responsive treatment and services in correctional settings. Women and Therapy, 29(3/4), 9-33.

Fazel, S., Doll, H., \& Langstrom, N. (2008). Mental disorders among adolescents in juvenile detention and correctional facilities: A systematic review and metaregression analysis of 25 surveys. Journal of the American Academy of Child and Adolescent Psychiatry, 47(9), 1010-1019.

Grisso, T. (2008). Adolescent offenders with mental disorders. The Future of Children, 18(2), 143-162.

Hawkins, J. D., Herrenkohl, T. L., Farrington, D. P., Brewer, D., Catalano, R. F., \& Harachi, T. W. (1998). A review of predictors of youth violence. In R. Loeber \& D. P. Farrington (Eds.), Serious and violent juvenile offenders: Risk factors and successful interventions (pp. 106-146). Thousand Oaks, CA: Sage Publications.

Holman, Barry., \& Ziedenberg, Jason. (2006). The dangers of detention: The impact of incarcerating youth in detention and other secure congregate facilities. Baltimore MD: Annie E. Casey Foundation.

Johansson, P., \& Kempf-Leonard, K. (2009). A gender-specific pathway to serious, violent, and chronic offending? Exploring Howell's risk factors for serious delinquency. Crime and Delinquency, 55, 216-240.

Kataoka, S., Zima, T., Dupre, D., Moreno, K., Yang, X., \& McCracken, J. (2001). Mental health problems and service use among female juvenile offenders: Their relationship to criminal history. Journal of the American Academy of Child and Adolescent Psychiatry, 40, 549-555.

Kim, J. Y. S., \& Fendrich, M. (2002). Gender differences in juvenile arrestees' drug use, dependency, and perceived need for treatment. Psychiatric Services, 53, 70-75.

Leiber, M. J., Brubaker, S. J., \& Fox, K. C. (2009). A closer look at the individual and joint effects of gender and race on juvenile justice decision making. Feminist Criminology, 4(4), 333-358.

Loeber, R., \& Keenan, K. (1994). Interaction between conduct disorder and its comorbid conditions: Effects of age and gender. Clinical Psychology Review, 14(6), 497-523.

Mallett, C. (2009). Disparate juvenile court outcomes for disabled delinquent youth: A social work call to action. Child and Adolescent Social Work Journal, 26(3), 197-208.

McCabe, K., Lansing, A., Garland, A., \& Hough, R. (2002). Gender differences in psychopathology, functional impairment, and familial risk factors among adjudicated delinquents. Journal of the American Academy of Child and Adolescent Psychiatry, 41(7), 860-867.

Office of Juvenile Justice and Delinquency Prevention. (2010). Girls delinquency. Office of Justice Programs, U.S. Department of Justice. http://www.ncjrs.gov/pdffiles1/ojjdp/228414.pdf.

Schwalbe, C. S., Hatcher, S., \& Maschi, T. (2009). The effects of treatment needs and prior social services utilization on juvenile court decision making. Social Work Research, 33, 31-40.

Shufelt, J. S., \& Cocozza, J. C. (2006). Youth with mental health disorders in the juvenile justice system: Results from a multi-state, multi-system prevalence study. Delmar, NY: National Center for Mental Health and Juvenile Justice.

Takeda, Y. (2000). Aggression in relation to childhood depression: A study of Japanese 3rd-6th graders. Japanese Journal of Developmental Psychology, 11(1), 1-11.

Teplin, L., Abram, K., McClelland, G., Dulcan, M., \& Mericle, A. (2002). Psychiatric disorders in youth in juvenile detention. Archives of General Psychiatry, 59(12), 1133-1143.

Teplin, L., Abram, K., McClelland, G., Mericle, A., Dulcan, M., \& Washburn, D. (2006). Psychiatric disorders of youth in detention. Juvenile Justice Bulletin. Office of Juvenile Justice and Delinquency 
Prevention, Office of Justice Programs, Washington DC. http://www.ncjrs.gov/pdffiles1/ojjdp/ 210331.pdf.

Timmons-Mitchell, J., Bender, M. B., Kishna, M. A., \& Mitchell, C. C. (2006). An independent effectiveness trial of multisystemic therapy with juvenile justice youth. Journal of Clinical Child and Adolescent Psychology, 35(2), 227-236.

Timmons-Mitchell, J., Brown, C., Shultz, S. C., Webster, S. E., Underwood, L. A., \& Semple, W. E. (1997). Final report: Results of a three year collaborative effort to assess the mental health needs of youth in the juvenile justice system in Ohio. Columbus, OH: Ohio Department of Youth Services.

Vaughn, M. G., Wallace, J. M., Davis, L. E., Fernandes, G. T., \& Howard, M. O. (2008). Variations in mental health problems, substance use, and delinquency between African American and Caucasian juvenile offenders: Implications for reentry services. International Journal of Offender Therapy and Comparative Criminology, 53, 311-329.

Wasserman, G., Ko, S., \& McReynolds, L. (2004). Assessing the mental health status of youth in juvenile justice settings. In Juvenile Justice Bulletin, 1-7. Washington DC: Office of Justice Programs.

Zahn, M. A. (2007). The causes of girls' delinquency and their program implications. Family Court Review, 45(3), 456-465. 